\title{
The Power of Place: The Effect of Forced Placement on Refugee Naturalization
}

\author{
Frederik Juhl Jørgensen \\ Department of Political Science, Aarhus University \\ fj@ps.au.dk
}

Does initial placement matter for refugee integration? I provide new evidence for the effect of placement on refugee integration. Using Danish register data, I exploit that refugees who obtained residency after January 11999 were subject to forced dispersal whereas refugees who obtained residency before this cutoff were subject to voluntary dispersal. In a regression discontinuity design, I show that forced dispersal — that induced exogenous variation in initial placement — had a large impact on refugees' likelihood of naturalization. Forced placed refugees are about 26 percent less likely to naturalize compared to voluntary placed refugees. Moreover, my findings suggest that this placement effect operates on a synergy mechanism between places and individuals' characteristics: forced placement affects refugee naturalization negatively because it deteriorates their ability to select into locations that match their own characteristics. Consistent with this mechanism, the drop in naturalization rates is concentrated among the most disadvantaged refugees. 
Many countries in Europe and the Americas have resettled an increasing number of refugees in the past decades. These refugees arrive in their host countries often very vulnerable, without many resources and facing many challenges integrating into the host societies. Consequently, refugee integration has become a fundamental policy challenge in these countries. A key issue is the question of ethnic residential concentration: widespread concern that ethnic residential concentration hinders refugees' integration has prompted policy makers across several traditional refugee receiving destination countries to adopt allocation policies that effectively disperse new refugees and balance ethnic compositions across geographic areas. This includes countries like Denmark, Sweden, Norway, the Netherlands, Germany, Switzerland, the United Kingdom, and the United States.

This raises the question: does placement matter for the integration of refugees? The debates about this question is characterized by two opposing views. The first view builds on the hypothesis that ethnic concentration slows down the rate of host country specific skill acquisition. According to this logic, living in an ethnic enclave provides less interaction with natives and reduces the incentives for acquiring host country specific human capital including language skills and host country specific knowledge (Chiswick and Miller 1995, 1996; Lazear 1999). In this logic, placement policies are seen as tool to promote refugee integration by providing a solution to the potential problem of ethnic concentration. The contrasting view stipulates that certain characteristics make a refugee a better match for a particular location, i.e., that there are synergies between places and individuals' characteristics (Bansak et al. 2018). In this logic, placement policies are seen as a barrier to refugee integration because they contribute to creating mismatches between individual refugee characteristics and placement locations by taking away refugees' ability to select into locations that match their own characteristics.

In this article, I contribute to these ongoing debates by focusing on the impacts of the Danish dispersal policy that is designed to direct new refugees away from immigrant-dense areas in 
the large cities and maintain them in their placed areas. It has two elements. First, it assigns all refugees to a specific municipality according to a pre-specified distribution key. Second, placement is forced in the sense that the policy stipulates that reception of social benefits is conditional on residing in the assigned municipality for the first three years. This essentially creates a geographical lock-in. In particular, I leverage that the Danish dispersion system was changed from January 1 1999: all refugees who obtained residency after January 11999 were subject to forced placement, whereas refugees who arrived earlier were placed on a voluntary basis. I exploit this discontinuity in a regression discontinuity (RD) design that enables me to isolate the independent effect of forced placement from the non-random selection into placement localities. In doing this, I obtain credible estimates for the causal integration effect of forced placement compared to voluntary placement.

My contribution differs from previous studies by focusing directly on the impact of (changes to) placement rules on refugee integration. Prior work have most commonly focused on effects of living in ethnic enclaves, which the placement rules of course are designed to influence. Moreover, relatively little research has been undertaken for refugees specifically and most of the previous studies face the problem that it is difficult to isolate the independent effect of ethnic concentration on integration because the place of residence and integration success or failure is not random. Rather, refugees select into neighborhoods with specific characteristics if they believe to benefit from its networks. This makes it a fairly hopeless endeavor — in traditional observational studies — isolating the independent placement effects from the plethora of confounding factors that simultaneously determine placement and affect the integration outcomes (e.g. Larsen 2011; Spicer 2008; Robinson and Coleman 2000; Robinson and Hale 1989; Robinson 1989; Bloch and Schuster 2005). The few studies that exploit quasi-random variation typically invoke quite strong assumptions about the randomness of the assignment mechanism into placement locations (e.g. Damm et al. 2009b; Edin et al. 2003; 
Martén et al. 2019; Battisti et al. 2016). In particular, these studies assume that placement is exogenous to individuals' unobservable characteristics, when conditioning on observable characteristics. This means that the studies stipulate that they are able to observe the full selection mechanism.

By estimating the effect of a change in placement rules, rather than the effect of living in ethnic clusters, I am able to replace the strong assumption of selection on observables by the much weaker selection on unobservables assumption ${ }^{1}$ (I discuss the specific assumption in detail in the research design section below). Moreover, I would argue that the direct impacts of placement on integration are more policy relevant than the impacts of living in enclaves because the latter can only be affected indirectly by policy, whereas allocation policies of course affect placement directly.

Setting methodological considerations aside, the above studies give mixed empirical results. Studies from Denmark and Sweden show positive effects on earnings for refugees (Damm et al. 2009b; Edin et al. 2003; 2004), but no impact on employment. To the contrary, Swiss and German evidence points to a positive, albeit short- to medium-term, employment effect, but no effects on earnings (Martén et al. 2019; Battisti et al. 2016). Research that moves beyond economic outcomes show effects on welfare dependency, tenure educational attainment, and crime rates (Åslund and Frederiksson 2009; Beaman 2011; Åslund et al. 2011; Damm and Dustmann 2014).

From a policy perspective, the lack of reliable causal evidence on the long-term integration impacts of placement policies on more broad measures of integration is concerning as it means that policy makers may not be fully aware of the consequences of their decisions when designing dispersal policies. I address this evidence gap and advance the literature in at least two respects. First, I solve the fundamental challenge of omitted variable bias by exploiting quasi-random variation in a

\footnotetext{
${ }^{1}$ More specifically, as I apply a regression discontinuity design, I assume that that the potential integration outcomes are continuous across the cutoff.
} 
RD design. Second, I move away from studying the short-term effects on economic outcomes. Instead, I focus on naturalization as a key indicator for integration and draw on Danish national registers to provide direct estimates for the long-term integration effect of forced placement on citizenship acquisition as of December 2015. By studying naturalization I provide new and policy relevant causal estimates for the integration effects of forced dispersal into the host society more broadly.

The study's main result is that forced placement lowers refugee naturalization success by about 26 percent. This sizable effect is robust across various robustness checks and contrasts the hypothesis that forced placement helps to solve the potential issue that ethnic concentration slows down the rate of host country specific skill acquisition. Instead, I show that forced placement affects refugee integration because it deteriorates their ability to select into locations that match their own characteristics. Thus, forced placed refugees remain less likely to naturalize when accounting for general location characteristics. Theoretically, this demonstrates that initial placement matters because there are synergies with individuals' characteristics. In addition, the results support the view that initial access to ethnic clusters can promote refugee integration. This means that although the forced placement policy achieves its immediate goal of placing new refugees in less ethnic concentrated areas, this in fact has a negative impact on refugee integration. Moreover, the findings show that this effect is driven predominantly by the less educated who face the largest resource constraints and difficulties in integrating into the host society at the outset.

These findings have clear implications for refugee allocation policies. With these policies, governments make it difficult for new refugees to select into places that match their own characteristics and, in particular, tap into social networks of co-ethnics. This means that host countries are decreasing refugees' chances of getting a good start on their new life. Instead, it creates barriers for their long-term integration. The findings suggest that governments should consider redesigning their allocation policies to maximize synergies between location and refugee characteristics (Bansak et al. 
2018) including a focus on existing immigrant networks (Martén et al. 2019). This could bring benefits for individual refugees as well as local societies.

\section{Does Forced Placement Affect Refugee Integration?}

The forced placement policy is designed to direct new refugees away from immigrant-dense areas in the large cities and maintain them in their placed areas. In addition to dispersing new refugees, the policy also stipulates that reception of social benefits is conditional on residing in the assigned municipality for the first three years, which essentially creates a geographical lock-in. One of the main motives for dispersing refugees in this way is the hypothesis that ethnic concentration slows down the rate of host country specific skill acquisition. According to this logic, living in an ethnic enclave provides less interaction with natives and reduces the incentives for acquiring host country specific human capital including language skills and host country specific knowledge, which negatively affects refugees' transition into employment (Chiswick and Miller 1995, 1996; Lazear 1999). In consequence, living in an ethnic enclave is viewed as a hindrance to labor market integration and a barrier for integration into the society more broadly. In this view, forced placement is seen as a tool to dilute the concentration of refugees. Consequently, forced placement can be expected to have positive integration effects by securing a better geographical distribution of new refugees and thereby immersing them to ethnically Danish local communities that should reduce their risk of becoming economically and socially marginalized in urban highly immigrant-dense areas.

The opposing view contends that forced placement is a barrier to refugee integration because it eliminates the individual's ability to select into locations that match their own characteristics. In this logic, certain characteristics make a refugee a better match for a particular location. That is, there are synergies between places and people that can be leveraged to optimize refugee integration (Bansak et al. 2018). Instrumentally, forced placement can be expected to hamper refugee integration 
because it creates mismatches between individual characteristics and placement locations. In particular, the geographical lock-in of the initial three-year period may very well exacerbate this problem. One important mechanism in this mismatch hypothesis may be social networks. From a social network perspective, locations matter because they can form a positive adaptive function of ethnic social networks and support. This makes initial placement crucial.

Instrumentally, social networks can offer assistance practical matters such as accessing health and other welfare services, and interpretation. Moreover, social networks may disseminate important information about job opportunities and thereby improve labor market integration as a first step toward broader integration into the host society (Portes 1987, 1998; Laezar 1999). Networks may also transfer knowledge about social norms to the individual (e.g., attitudes toward welfare receipt, norms about early marriage, educational attainment of women, work ethics, and division of labor between spouses) that influence their integration (Coleman et al. 1966; Wilson 1987; Case and Katz 1991; Bertrand, Luttmer, and Mullainathan 2000). Psychologically, networks may reduce feelings of isolation and depression and help develop confidence and self-esteem through the emotional and financial support they might offer (Bertrand, Luttmer, and Mullainathan 2000; Chiswick and Miller 2005; Spicer 2008; Boswell 2001; Burnett and Peel 2001; Sales 2002; Zetter and Pearl 2000). Furthermore, ethnic networks may provide an environment that guard against the discrimination from natives that are found elsewhere (Portes 1998).

The above discussions also raise the important question of potential effect heterogeneity. Thus, the forced placement effect may very well be contingent on refugee characteristics rather than uniform across refugees. One expectation is that effects are contingent on education level. In particular, models featuring human capital externalities - that emphasize the quality of the ethnic enclave, e.g., the stock of human capital (Borjas 1995, 1998; Cutler and Glaeser 1997)—stipulates that disadvantaged member of an ethnic group benefit from living in enclaves with more advantaged 
members of the group. This makes for the prediction that potential negative effects are concentrated among the less educated who face the largest resource constraint, while the better educated and more advantaged may benefit from forced placement.

\section{Citizenship Acquisition as a Key Indicator for Integration}

Danish citizenship law is based on a jus sanguinis principle and did not follow European trends in the 2000s, where many countries extended citizenship entitlements, accepted multiple citizenship and introduced jus soli elements to facilitate naturalization. Instead, Denmark made conditions for citizenship acquisition more restrictive (Ersbøll, 2015). To be eligible for Danish citizenship, by 2015, refugees' had to satisfy eight conditions. ${ }^{2}$ First, for refugees, Denmark has a residence requirement of 8 years of uninterrupted stay. Second, it is required that the refugee holds a permanent permit. Third, a conduct requirement excludes refugees from naturalization if they have been sentenced to imprisonment for eighteen months or more (Ersbøll, 2015). Fourth, proficiency in the Danish language is required. The requirement is currently at the Council of Europe level B1. Fifth, refugees must be self-sufficient. This implies that a refugee cannot have received social benefits within the last year of naturalization and cannot have received social benefits for more than an aggregate period of six months period within the last five years of naturalization. Sixth, the applicant cannot be considered for citizenship if she has due debt to the state. Seventh, the applicant has to deliver a declaration of allegiance and loyalty to Denmark and declare that she will comply with Danish law. Finally, the applicant has to pass a citizenship test that focuses on aspects of everyday life, Danish culture, history, and political life.

\footnotetext{
${ }^{2}$ Recently, the government added a ninth condition: Applicants have to participate in a ceremony to show respect for Danish values and representatives of the Danish authorities.
} 
In sum, the threshold for Danish citizenship acquisition is relatively high, which suggests that naturalization may be a good indicator for important integration aspects into the Danish society more broadly. In particular, the eight conditions above tap into important dimensions of the integration concept, including linguistic integration, economic integration, psychological integration, cultural integration, political integration, and social integration. Similarly, naturalization is often used as a key measure of overall integration success in the literature (Mossaad et al. 2018). Thus, Hainmueller and Hangartner (2013) show that naturalization is an important overall indicator of successful linguistic, political, and economic integration. Moreover, Harder et al. (2018) show these dimensions of integration to be highly correlated with other dimensions including social, psychological, and navigational integration. Furthermore, citizenship acquisition has been shown to catalyze further economic, political, and social integration (Hainmueller, Hangartner, and Pietrantuono 2015, 2017; Hainmueller Hangartner, and Ward 2019). Finally, with a mean sample rate of about 50 percent, citizenship acquisition is not a marginal phenomenon in Denmark. Taken together, this means that citizenship status may be a good indicator for long-term integration into the Danish society more broadly.

\section{Research Design}

\section{The Danish Dispersal Policy}

In 1986, the first policy that dispersed refugees upon approval of their asylum application was implemented. This followed a period with a marked increase in asylum applications in Denmark in the 1980s that made it increasingly difficult for the Danish Refugee Council (DRC) to satisfy the location preferences of most new refugees (Damm 2009a, 2010). Under the charge of DRC, this spatial dispersal policy was in force until January 1 1999. In practice, refugees were offered assistance to find housing immediately upon approval of their asylum application. If the individual accepted, she would 
fill in a form about her background including family relations and nationality. The DRC would then assign the individual to one of 15 counties approximately 10 days later.

Having provided temporary housing in the receiving county, local offices assisted in finding permanent housing within the county (Damm 2009a, 2010). Approximately 90 percent of the refugees were provided with or assisted by the DRC in finding permanent housing under the terms of the dispersal policy (Damm 2005b). This spatial dispersal was a two-stage process. Across counties, the DRC tried to distribute refugees evenly according to their relative number of inhabitants. At the county level, the DRC aimed at balancing the number of refugees across municipalities with suitable housing, educational institutions, opportunities of employments, and conationals. Importantly, however, placement was voluntary. Thus, refugees faced no restrictions on relocation and were allowed to relocate freely at any time without any sanction in regard to receipt of social benefits (Damm 2009a, 2010).

January 11999 marks an important shift in Danish integration policy. The Social Democratic government introduced Denmark's first Integration Act (Integrationsloven) that affected all new refugees who obtained residency after January 1 1999. Refugees with a residency date before January 1999 were subject to the old rules. The law moved the integration responsibility from the DRC to the municipalities and reformed the dispersal system. Thus, all refugees with a residency date after January 11999 would be dispersed across municipalities according to a pre-specified distribution key ${ }^{3}$. Moreover, placement in the assigned municipality was mandatory for the first three years. Thus, in contrast to the previous rules, reception of social benefits was conditional on residing in the assigned municipality for a three-year period. That is, refugees could only move if they found a job in a different municipality. This de facto created a geographical lock-in. Note, however, that the new

\footnotetext{
${ }^{3}$ This key is computed as the municipality's share of the total population subtracted the difference between the municipality's share of the total number of immigrants and refugees and the municipality's share of the total population.
} 
dispersion rules de facto did not apply to refugees that obtain residency after January 1 but have a spouse who obtained residency before the cutoff because they are settled with their spouse.

According to the Danish Ministry of Integration, the new dispersion rules should both ensure a better geographical distribution of new refugees and at the same time secure that they remain in their assigned municipalities. The intention of the policy was to promote refugee integration by exposing new refugees to ethnically Danish local communities that should reduce their risk of becoming economically and socially marginalized in urban highly immigrant-dense areas. Under the former rules (before 1999) refugees were thus located mainly in urban areas with relatively large immigrant and refugee populations whereas the new law successfully dispersed newly arrived outside urban municipalities (Larsen 2011; Nielsen and Jensen 2006) ${ }^{4}$.

\section{Empirical Strategy}

I exploit the discontinuity in Danish dispersal policy in a regression discontinuity (RD) design that identifies the forced placement effect on naturalization on the assumption that the potential naturalization outcomes are continuous across the cutoff of January 11999 (Hahn, Todd, and Van der Klaauw 2001). If the continuity assumption is valid, the RD design provides a local experiment that - in the same way as a randomized experiment — isolates the causal effect of forced placement compared to voluntary placement at the cutoff. This estimate reflects an intention-to-treat effect of dispersal versus non-dispersal given that it identifies the impact of changing placement policies from a voluntary system where refugees can freely relocate to a forced system with sanctions that prevent relocation. It

\footnotetext{
${ }^{4}$ The Integration Law, moreover, expanded the introductory integration program - that includes language courses and is mandatory for refugees to participate in - from $1 \frac{1 / 2}{2}$ years to 3 years. Finally, it also stipulated that refugees would receive introductory benefits-somewhat below regular social assistance-during this period (Nielsen and Jensen 2006). However, because of pressure from the UNHCR and a government evaluation that showed that the lower benefits did not have the desired effects, the introductory benefits were revoked shortly after their implementation.
} 
should, accordingly, be interpreted as a lower bound for the comparison of dispersed and non-dispersed refugees. The identifying assumption fails if refugees sort around the cutoff, which would only happen if they can manipulate their date of residency. Manipulation could occur in two distinct stages.

In the first stage, refugees decide whether to apply for asylum in Denmark or not. Causal attribution is problematic if refugees were able to anticipate the reform. If this was the case, one might expect the reform to change the composition of refugees above the cutoff compared to refugees below. In particular, one could be worried that refugees with sufficient knowledge — who would most likely also have more resources to integrate into the host society-stopped applying for asylum if they risked obtaining residency after the cutoff. In the second stage, decision-makers that review asylum applications could cause a more subtle source of confounding. They typically decide on a much more informed basis about applicants than what the researches observes. If decision-makers prefer specific groups of refugees to others based on unobservable factors, this could create bias in the causal estimates.

However, there is strong justification for expecting that the assumption of no sorting across the cutoff is valid in this application. First stage selection is only a concern if refugees had sufficient information to anticipate the reform. There is good reason to expect that refugees, in fact, lacked this information. Thus, the reform was implemented over a 6 months period. ${ }^{5}$ A mean asylum application processing time of about 5 months and considerable variation in processing times (Flygtningenævnet 1999) makes it very unlikely that refugees were able to anticipate the cutoff and submit an asylum application in due time to get under the old placement rules. Second stage selection, however, remains a concern, but three factors alleviate these concerns and contribute to the quasi-random variation of placement across the cutoff. First, the Danish Immigration Service - that decides whether there is a basis for granting asylum — bases its decision entirely on the legal criteria of the applicant's

\footnotetext{
${ }^{5}$ The reform was adopted July 11998 with effect from January 11999.
} 
need for protection. Second, decision-makers would not only have to prefer certain types of refugees to other, but also process their applications faster for it to generate bias. Third, I control for a rich set of covariates as observed in the registers.

Altogether, this suggests that the RD design recovers the causal effect of forced placement on naturalization. However, it is important to recognize that the validity of the continuity assumption is ultimately an empirical question. I return to this assessment below.

\section{Data}

My source of data is the Danish national registers. I select all refugees who obtained residency within a bandwidth of \pm 183 days (i.e., $1 / 2$ a year) from the cutoff January 11999 cutoff. However, I show that results are relatively insensitive to varying the width of the estimation window (see Figure S.1 in the supplementary information (SI)). I focus only on refugees because this is the only immigrant group that is systematically affected by the reform. I exclude refugees who have spouses that obtain residency outside this bandwidth. Moreover, I only include refugees who at the time of residency were adults at their time of residence (i.e., at least 18 years old).

In this group of refugees, I use the registers personal identifier to construct a dataset that links information on refugees' exact date of residency (i.e., information on the treatment) and information on the outcomes. Refugees above the cutoff are assigned 1 on the treatment indicator, whereas refugees below the cutoff are assigned 0 . As the new dispersion rules de facto did not apply to new refugees whose spouse obtained residency before the cutoff (see explanation above), the treatment indicator also takes the value 0 if refugees arrive above the cutoff but their spouse arrive below. To ensure consistency between the treatment indicator and the date of residency, I assign the de facto untreated refugees — whose spouse arrive below the cutoff — their spouse's date of residency. One alternative way of handling this inconsistency between the treatment indicator and date of residency 
would be to exclude spouses who obtain residency after the cutoff, but are de facto under the old rules. Note that this alternative produces substantively similar results (see Table S.7 in the SI).

As discussed above, I take citizenship acquisition as a key measure of integration and my main outcome (citizenship status is measured by December 31 2015). To explore the mechanisms that link forced placement and citizenship acquisition, I use secondary migration (i.e., refugees' likelihood of staying in their assigned municipality) and local social networks (measured as local concentrations of co-ethnics and immigrants) as alternative outcomes. I merge the treatment and outcome data with background characteristics of the individual refugee based on the personal identifier as well as unique spouse and family identifiers. These covariates include sex, age, education, grouped origin ${ }^{6}$, whether the refugee is married or not, and whether the refugee has children or not. Table 1 provides descriptive statistics for all variables described above for refugees within the bandwidth of \pm 6 months of the July 1 cutoff. The top panel of the figure presents the treatment data, the middle panel the individual characteristics, and the bottom panel the outcome data.

\footnotetext{
${ }^{6}$ Note that including the full set of country of origin dummies in the estimations produce essentially identical results as including the origin cluster dummies or leaving out control variables (see Table S.8 in the SI). Given local randomization at the cutoff, this is exactly what one would expect.
} 
Table 1. Descriptive Statistics for Refugees within the \pm 6 Months Bandwidth

\begin{tabular}{lcccc}
\hline \hline Variable & Mean & SD & Min & Max \\
\hline Forced placement indicator & 0.32 & 0.47 & 0.00 & 1.00 \\
Residency date (centered on the cutoff) & -25.66 & 106.07 & -183 & 182 \\
\hline Female & 0.46 & 0.50 & 0.00 & 1.00 \\
Age & 33.76 & 11.68 & 18.04 & 87.60 \\
Education (months) & 137.28 & 41.32 & 0.00 & 204.00 \\
Married & 0.68 & 0.47 & 0.00 & 1.00 \\
Children & 0.46 & 0.50 & 0.00 & 1.00 \\
Grouped origin & & & & \\
East or Central Europe & 0.28 & 0.45 & 0.00 & 1.00 \\
Middle East & 0.56 & 0.50 & 0.00 & 1.00 \\
Africa & 0.16 & 0.37 & 0.00 & 1.00 \\
- Citizenship & 47.88 & 49.97 & 0.00 & 100.00 \\
Social networks & & & & \\
Local conc. co-ethnics & 5.44 & 8.40 & 0.09 & 49.42 \\
Local conc. immigrants & 10.63 & 12.19 & 0.26 & 58.84 \\
Inter-municipality migration (stay) & & & & \\
2000 & 67.21 & 48.24 & 0.00 & 100.00 \\
2001 & 62.97 & 49.20 & 0.00 & 100.00 \\
2002 & 58.30 & 49.62 & 0.00 & 100.00 \\
2003 & 53.82 & 49.87 & 0.00 & 100.00 \\
2004 & 51.27 & 50.00 & 0.00 & 100.00 \\
2005 & 48.85 & 50.00 & 0.00 & 100.00 \\
2006 & 47.64 & 49.96 & 0.00 & 100.00 \\
2007 & 35.27 & 47.80 & 0.00 & 100.00 \\
\hline \hline
\end{tabular}

Note: All variables are measured in the Danish administrative registers. The top panel of the table presents the treatment data. The middle panel presents all individual background characteristics that are measured by the date of residency (i.e., the first entry in the registers). The bottom panel presents the outcome measures. Citizenship is measured as of December 31 2015. The social network outcomes are measured by the end of the refugees' first full year of residency. $N=1,650$.

\section{Results}

In the results section below, I estimate the effect of forced placement by regressing citizenship status on the treatment indicator, residency and the interaction between the two within a bandwidth of \pm 183 days, i.e. $1 / 2$ year, from the cutoff. Figure S.1 shows that the effect estimates are remarkably stable over varying bandwidths. To further probe the robustness of the findings, Table S.9 shows that estimates are essentially similar when using a local polynominal specification instead of the local linear. 
Moreover, as I argue below, the identification checks indicate that the RD design is able to isolate the causal effect of forced placement at the cutoff.

\section{Empirical Assessment of the Continuity Assumption}

Although the validity of the continuity assumption cannot be tested directly, the causal logic of the RD design, nevertheless, opens for indirect tests. Thus, the design is based on the logic that the forced placement date cutoff is an arbitrary date. This means that refugees with residency just before the cutoff should be similar in all confounding characteristics to refugees with residency just after the cutoff. The right panel of Figure 1 shows a series of placebo outcome checks where I tested for discontinuities in individual background characteristics at the forced placement cutoff. The distribution of $P$ values is consistent with the uniform distribution that one would expect for balance in a randomized experiment. This indicates that there was no systematic discontinuities in the covariates at the cutoff.

The left panel of Figure 1 shows a placebo test where I estimate the effect at the forced placement cutoff among non-refugee immigrants who were unaffected by the policy change. If the treatment effect among refugees is indeed a consequence of the policy change rather than an artefact of randomness in the naturalization outcome, then one should not expect to find any discernible difference among unaffected immigrants. The difference in naturalizations at the cutoff was an insignificant 0.32 percentage point increase $(P<0.777$; local linear regression). Building on a similar logic, Figure S.2 in the SI shows that there are no discontinuities at placebo cutoffs above and below the true cutoff. Moreover, Figure S.1 demonstrates that effect estimates are remarkably stable across varying widths of the estimation window.

Figure S.3 in the SI displays McCrary's (2008) test for sorting around the cutoff. This test indicates that there is a downward jump in the densities at the cutoff of January 11999 . This 
raises some concern over manipulation of the forced placement cutoff. However, Figure S.3 shows similar differences in the densities at the cutoff of January 11998 and January 12000 , respectively. Taken together, this alleviates the concern that the difference in densities is due to strategic behavior of the refugees. Instead, it suggest that it rather be due to random forces. This is also corroborated by the qualitative argument that refugees' lacked the necessary information to anticipate the forced placement cutoff (cf. above). Moreover, had the difference in densities indeed reflected sorting, one should expect refugees' to differ in their confounding characteristics at the cutoff. Instead, as Figure 1 showed, all confounding characteristics were well balanced across the forced placement cutoff. Taken together these identification tests suggest that the RD design provides a local experiment that is able to isolate the causal effect of forced placement compared to voluntary placement at the cutoff.

Figure 1. Identification Checks for the RD Design

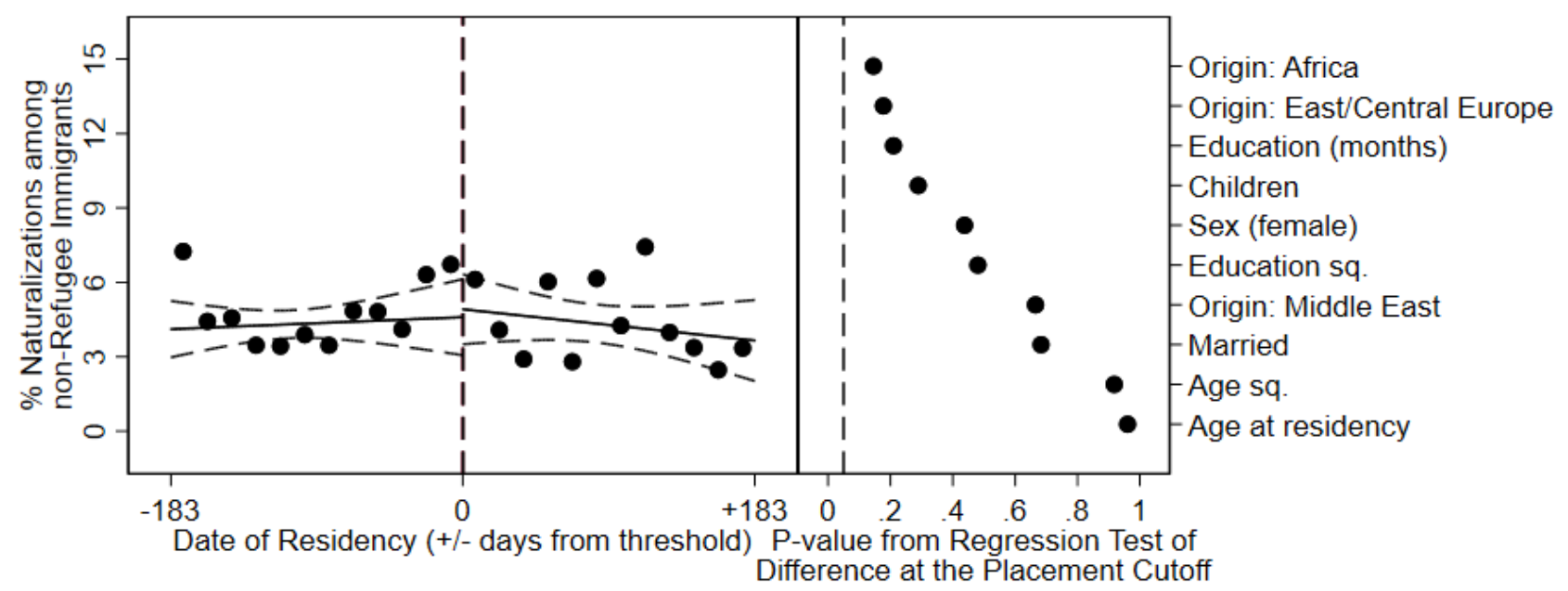

Note: Left panel shows the placebo RD effect estimate among non-refugee immigrants. Solid lines are average naturalization rates (with 95\% confidence intervals) from local linear regressions within a bandwidth of \pm 183 days from the placement cutoff and circles are binned averages. There was no discernible difference in naturalization rates among non-refugee immigrants. Right panel shows $P$ values from placebo outcome tests and demonstrates that there was no statistical evidence for discontinuities in background characteristics that potentially confound the comparison at the cutoff. 


\section{Overall Effect on Naturalization}

As explained in the theory section, one of the main motives for forced placement is the hypothesis that ethnic concentration slows down the rate of host country specific skill acquisition. This potential skill acquisition mechanism makes for the prediction that forced placement has a positive impact on naturalization. To the contrary, the synergy mechanism stipulates that forced placement could affect naturalization negatively. Figure 2 tests these two contrasting predictions and illustrates the main findings (Table S.1 reports the supporting regression table). The left panel displays the graphical results of applying the RD design, whereas the right panel displays the marginal difference in naturalization rates at the cutoff from regression models with and without covariates, respectively. The percent of refugees who acquire citizenship dropped by about 13 percentage at the forced placement cutoff $\left(\alpha_{\mathrm{w} / \mathrm{o} \text { covs }}=-12.79\right.$ percentage points, $P<0.033 ; \alpha_{\text {with covs }}=-14.20$ percentage points, $\left.P<0.005\right)$. This is equivalent to a marked 26 percent reduction compared to the counterfactual mean naturalization rate at the cutoff $(\approx 50$ percent $)$. The inclusion of covariates checks the design based identification: if refugees who obtain permits just before and after the cutoff are similar in all confounding respects - as local randomization stipulates - then including or excluding covariates should not substantially alter the effect estimate. Consistent with the placebo outcome tests above, the effect is very stable across the models with and without covariates.

In stark contrast to the hypothesis that forced placement promotes the acquisition of host country specific skills and subsequently has a positive effect on the likelihood of naturalization, these results suggest that forced placement has a substantial negative impact on refugee naturalization. The results are striking as I compare refugees who are identical in terms of their background characteristics but separated by only a few days with regard to residency. Moreover, as discussed above the estimates may be interpreted as a lower bound on the effect of dispersal relative to nondispersal. 
Figure 2. Overall Effect on Naturalization from Applying the RD Design

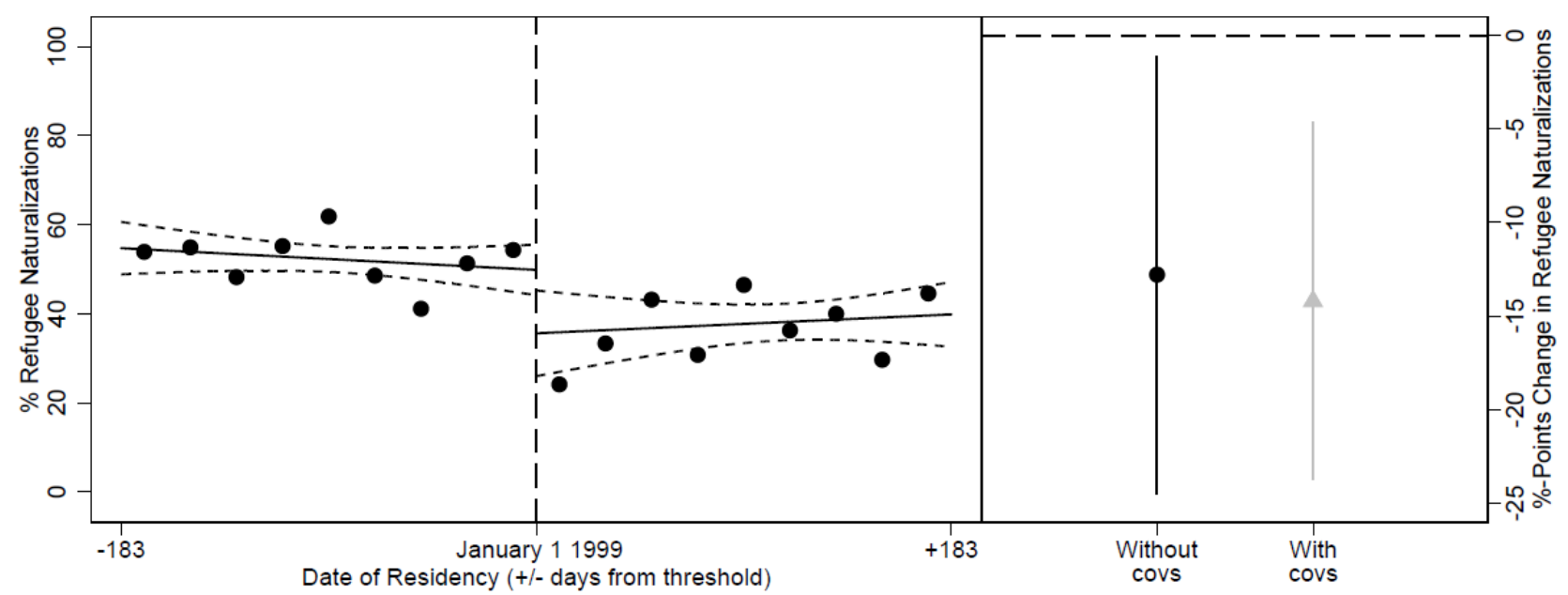

Note: Left panel displays the graphical overall result on naturalization from applying the RD. Lines are average naturalization rates (with 95\% confidence intervals). Right panel displays the regression results for models without and with covariates (with 95\% confidence intervals), respectively. Standard errors are clustered by first municipality. $\mathrm{N}=1,650$.

\section{The Underlying Mechanisms}

While the finding above suggests that forced placement $d o$ not affect refugee naturalization through the skill acquisition mechanism, it remains an open question whether the negative effect estimates predominantly reflect that there are synergies between individual characteristics and placement locations or some alternative mechanism. While forced placed refugees faced economic sanctions if they relocated away from their assigned municipality in their first three years of residency, voluntary placed refugees could freely move. Against this backdrop, one implication of the synergy mechanism is that voluntary placed refugees, in their first years of residency, can be expected to relocate across municipalities at higher rates relative to forced placed refugees. Another implication is that the relocation gap should slowly close over time as forced placed refugees become able to relocate freely. 
To test these propositions, I replicated the RD models with inter-municipality migration as the outcome. ${ }^{7}$ In particular, the outcome measures refugees' likelihood of staying in their assigned municipality. Figure 3 displays the average probability of staying in the assigned municipality by placement groups (it takes the value 100 if the refugee stayed in her assigned municipality and 0 if she moved away). The figure shows a large initial difference between forced and voluntary placed refugees' likelihood of remaining in their assigned municipality: after one year, about 37 percent of the voluntary placed refugees have relocated, whereas only 14 percent of the forced placed refugees have moved away. As expected, this difference in migration rates slowly begins to narrow after 2002, where the forced placement group no longer face relocation sanctions. From 2006, there is no longer a statistically significant difference between the two groups' migration rates. ${ }^{8}$ Although the results indicate that there is a mismatch between the initial placement of refugees and their individual characteristics, it remains unclear whether this reflects a general location effect that some places are unconducive to refugee integration or the more refined synergy story that certain characteristics make a refugee a better match for a particular location. Separating these two mechanisms would have important consequences for the design of refugee allocation policies.

To get at the underlying mechanism, I first try to net out any general location effects from the estimated RD effects on citizenship acquisition to get at only the synergy effects. I trim the sample to include only forced placed refugees who remained in their assigned municipality for the first three years. I match this group of refugees with voluntary placed refugees who after three years

\footnotetext{
${ }^{7}$ I do not observe refugees' assigned municipality. Instead, I use the first observed municipality as a proxy for assignment municipality. For each year, refugees are assigned the value 100 if they stay in their first observed municipality and zero if they have moved away.

${ }^{8}$ Table S.2 in the SI shows the supporting regression table, where I regress the secondary migration outcome on the forced placement indicator, residency, and the interaction between the two. The table show how the initial differences are large and significant, whereas the differences become smaller and insignificant in the long-term.
} 
live in one of the same municipalities. In this matched sample, I replicate the RD models with naturalization as the outcome. This means that I compare refugees that live in the same municipalities, but while the latter group lives there voluntarily the first group is forced to. The logic of this comparison is that any remaining difference between the groups reflects the synergy mechanism, i.e., a mismatch between location and individual refugee characteristics.

Figure 3. The Synergy Hypothesis: RD Effects on Inter-Municipality Migration

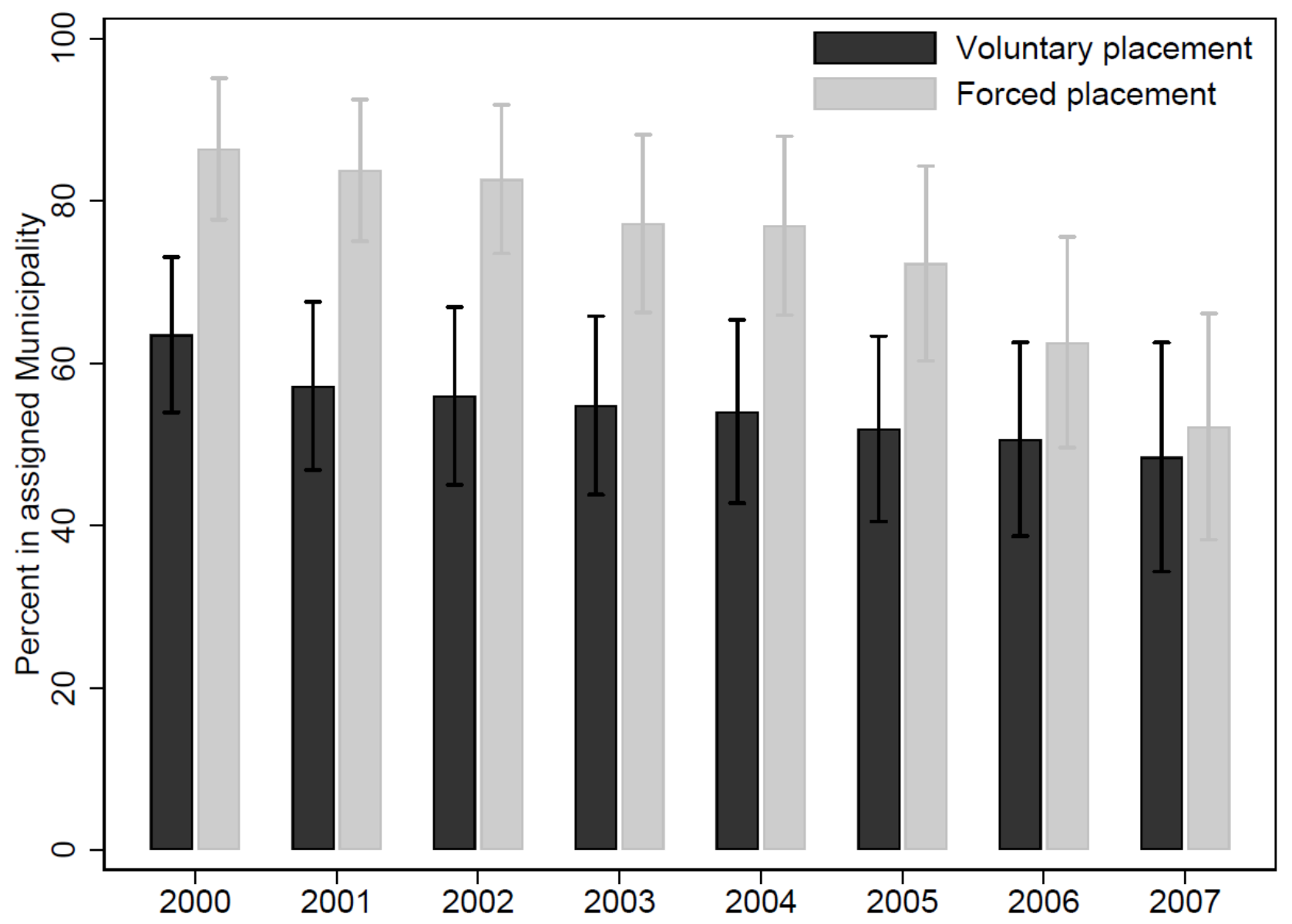

Note: Means at the cutoff with $95 \%$ confidence intervals. Based on RD models w/o covariates. Standard errors are clustered by first municipality. Bandwidth \pm 6 months. $\mathrm{N}=1,650$. 
The result, displayed in the left panel of Figure 4, shows a clear drop in naturalization rates at the cutoff. In fact, the percent of refugees who acquired a citizenship dropped by about $16^{1 / 2}$ percentage points ( $\alpha_{\mathrm{w} / \mathrm{o} \text { covs }}=-16.61$ percentage points, $P<0.034$ ), which is in fact slightly larger than the overall sample estimate (Table S.3 in the SI reports the supporting regression table). ${ }^{9}$ Following the logic from above that this test nets out any general location effects, this provides evidence that the forced placement effect is predominantly driven by the synergy mechanism. This means that two refugees of similar backgrounds (i.e., similar ethnic background, of similar age, same sex, similar family situation, and similar educational levels) follow very different integration paths when settled in different placement locations. While one thrives, the other struggles in integrating into the host society. Forced placement affects refugee integration negatively because it eliminates refugees' ability to select into places that match their characteristics.

Table S.4 in the SI shows the robustness of the matched sample forced placement effect across various placement locations. In particular, it demonstrates that forced placement in larger as well as in smaller cities decrease refugees' likelihood of naturalization. These results, address the objection that the forced placement effects are driven by characteristics of specific places, where refugees are more likely to be placed after the dispersal reform. An objection to the interpretation above would thus be if the forced placement effect were driven by placement in smaller cities. The robustness of the results demonstrates that this is not the case.

\footnotetext{
${ }^{9}$ This increase reflects that a small proportion of the forced placed refugees move out of their assigned municipality - which would happen only if they found a job in another municipality - for whom there is a positive, albeit insignificant, reform effect that factors into the overall effect estimate.
} 
Figure 4. Synergy or General Location Effect?

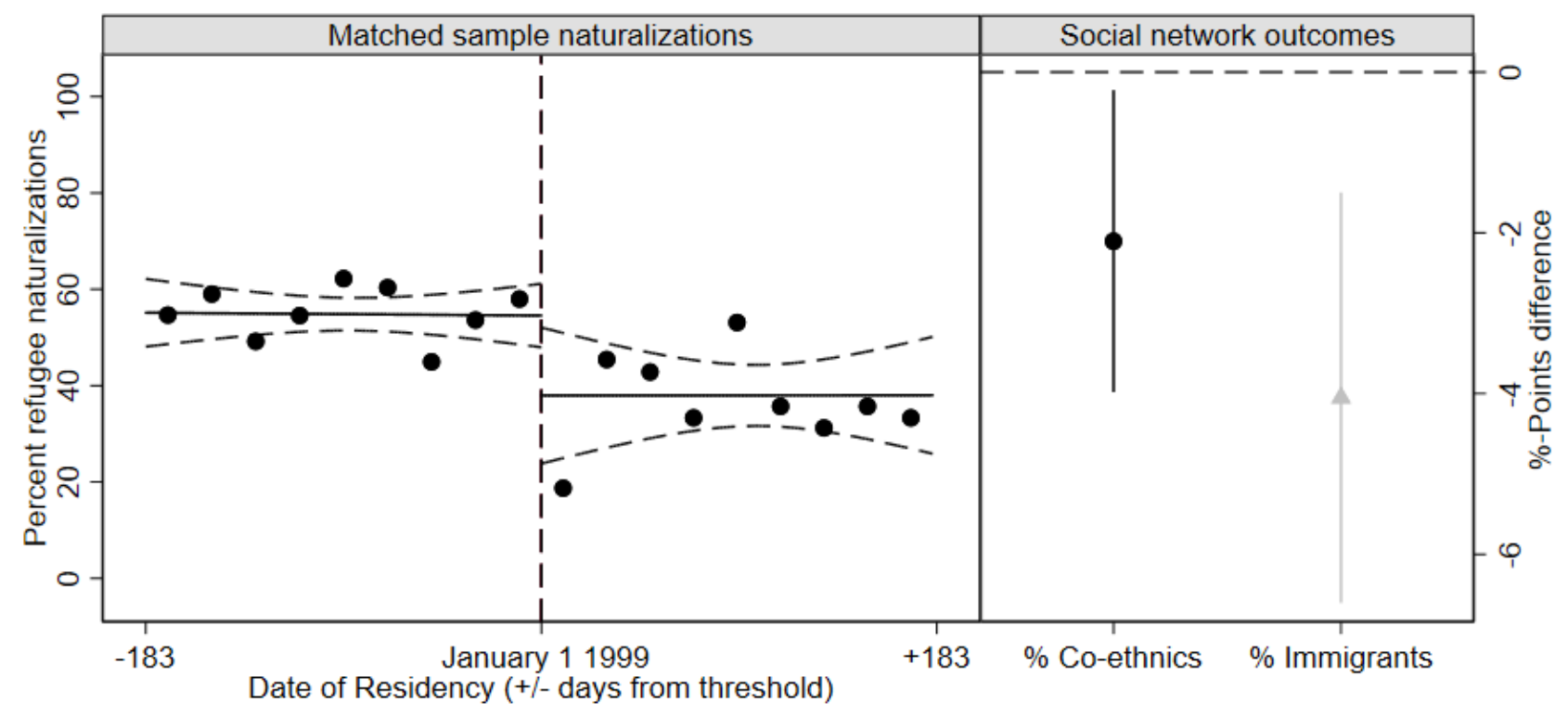

Note: Left panel displays the result of applying the RD design graphically. Lines are average naturalization rates (with 95\% confidence intervals) on each side of the cutoff. $\mathrm{N}=1,055$. Right panel displays the marginal RD effect estimates (with $95 \%$ confidence intervals) on social network outcomes. $\mathrm{N}=1,650$. (RD models w/o covariates. Standard errors are clustered by first municipality. Bandwidth \pm 6 months).

Until now, I have been unconcerned about the factors that shape the synergies between place and individuals. As discussed in the theory section, one crucial aspect of the synergies may be social networks that potentially forms a positive adaptive function of support. To get at the proposition that deterioration of social networks is an important driver of the effect of forced placement, I follow previous research and measure neighborhoods' conduciveness to the formation of social networks using as indicators local concentrations of co-ethnics and immigrants (Habyarimana et al. 2007; Algan et al. 2016; Damm 2009a; Åslund 2005; Damm and Rosholm 2010). If social networks are an important factor in the synergies between place and individual, one should expect a negative forced placement effect on these alternative outcomes. The right panel of Figure 4 shows that forced placement markedly lowers the initial local concentration of co-ethnics $\left(\alpha_{\text {co-ethnics }}=-2.10\right.$ percentage points, $P<0.029)$ and immigrants $\left(\alpha_{\text {immigrants }}=-4.05\right.$ percentage points, $P<0.003$ ). (Table S.5 in the SI provides the supporting regression table). On each measure, this corresponds to decreases of about 
$1 / 3$ compared to the counterfactual mean. Overall, this indicates that social networks are one important factor that shapes the synergies between places and individuals. It also raises the important question of effect heterogeneity because one might expect that certain groups rely more strongly on social networks than others do.

\section{Effect Heterogeneity}

As discussed in the theory section, the negative forced placement effect can be expected to be concentrated among the less educated who face the largest resource constraints and can be expected to benefit the most from living in enclaves with more advantaged members of the same ethnic group. To the contrary, the better educated may benefit from forced placement given that they already possess the necessary capabilities to integrate into the host society. I test these expectations by separately estimating the forced placement effect within education subgroups: I split education into low, medium, and high educated. ${ }^{10}$ Figure 5 displays the results of these subgroup analyses. The figure shows an empirical pattern that is consistent with the theoretical predictions. Thus, the negative effect is concentrated among the low educated $\left(\alpha_{\text {low educated }}=-21.04, P<0.004\right)$, whereas the estimate decrease and is insignificant among the medium educated $\left(\alpha_{\text {medium educated }}=-6.59, P<0.587\right)$, and turns positive for the high educated who experience an insignificant increase in their likelihood of naturalization $\left(\alpha_{\text {high educated }}=10.08\right.$ percentage points, $\left.P<0.555\right)$.

Theoretically, these findings align with recent work (e.g. Marbach et al. 2018, Hainmueller et al. 2016) that points to the existence of an influential early integration window that affect

${ }^{10}$ I define low education as less than or equal to 120 months. This corresponds to $10^{\text {th }}$ grade in the Danish primary school. Moreover, to this group I also add refugees whose education level is unknown. Medium education is defined as more than 120 months, but less than 180 months that corresponds to a bachelor's degree. Finally, high education is more than 180 months. 
refugees' subsequent integration trajectory disproportionately. From a policy standpoint, this is especially concerning because it shows that forced placement marginalize those who have little chances of integrating into the host society further and push them to the edges of the society.

Figure 5. Are the Forced Placement Effects Heterogeneous?

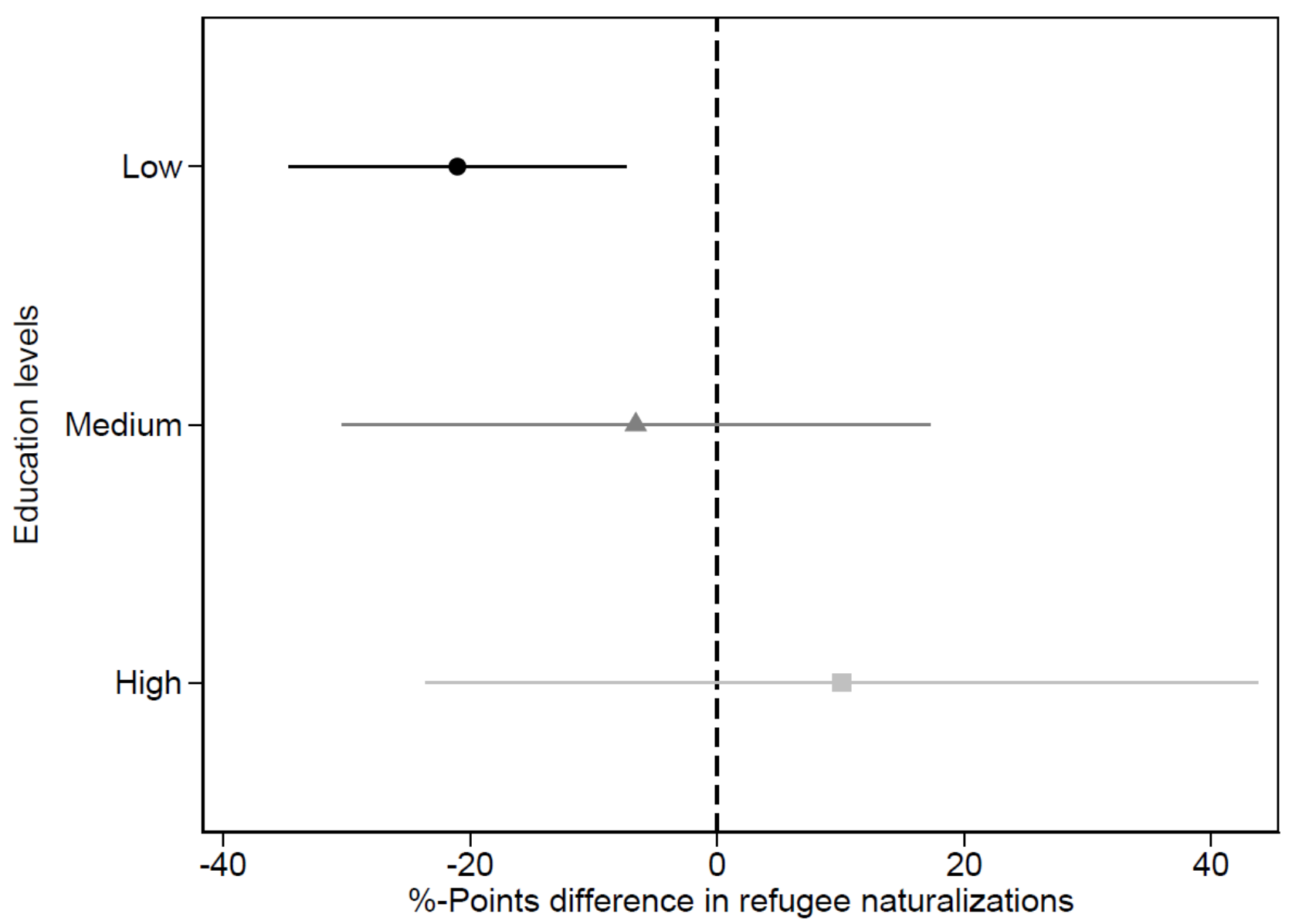

Note: RD effect estimates with $95 \%$ confidence intervals. Standard errors are clustered by municipality. Bandwidth \pm 6 months. $\mathrm{N}($ low $)=725 ; \mathrm{N}($ medium $)=666 ; \mathrm{N}($ high $)=259$.

\section{Conclusion}

In this study, I provide new and causally relevant estimates for the effect of forced placement that contributes to the important debate over the influence of place. The results show that forced placement, on average, lowers refugee naturalization by about 13 percentage points. This corresponds to a 
decrease of about 26 percent. This is striking as I compare refugees who are identical in terms of their background characteristics but separated by only a few days with regard to residency. Moreover, the estimated effects provide a lower bound for the effect of dispersal relative to non-dispersal given that the design compares forced placed to voluntary placed refugees.

The findings are crucial for both theory and the design of policy. For theory, the results do not square with the skill acquisition hypothesis that contends that forced placement has a positive effect on refugee integration because it dilutes ethnic concentrations that would otherwise slow down the rate of host country specific skill acquisition. Instead, the results support the view that initial access to ethnic clusters can promote refugee integration. While forced placement achieves its immediate goal of placing new refugees in less ethnic concentrated areas, this simultaneously has a negative impact on refugee integration. Moreover, it is clear that this effect is driven predominantly by the less educated who face the largest resource constraints and difficulties in integrating into the host society at the outset. Taken together, these findings contribute to our theoretical understanding of the importance of initial placement and social networks for refugee integration. Moreover, the findings have important implications for refugee allocation policies.

For policy, this have clear implications for the way that allocation policies - that have been adopted by several European governments to specifically disperse and balance the distribution of refugees geographically—should be designed. By adopting allocation policies with forced placement elements, governments make it difficult for new refugees to select into places that match their own characteristics and, in particular, tap into social networks of co-ethnics. In fact, this means that host countries are decreasing refugees' chances of getting a good start on their new life. Rather it creates barriers for their long-term integration. Instead, the results suggest that governments should 
consider redesigning allocation policies to maximize synergies between location and refugee characteristics (Bansak et al. 2018) including a focus on existing immigrant networks (Martén et al. 2019). This could bring benefits for individual refugees as well as local societies. 


\section{References}

Bansak, K., Ferwerda, J., Hainmueller, J., Dillon, A., Hangartner, D., Lawrence, D., \& Weinstein, J. (2018). Improving refugee integration through data-driven algorithmic assignment. Science, 359(6373), 325-329.

Battisti, M., Peri, G., \& Romiti, A. (2016). Dynamic effects of Co-Ethnic networks on immigrants' economic success (No. w22389). National Bureau of Economic Research.

Beaman, L. A. (2011). Social networks and the dynamics of labour market outcomes: Evidence from refugees resettled in the US. The Review of Economic Studies, 79(1), 128-161.

Bertrand, M., Luttmer, E. F., \& Mullainathan, S. (2000). Network effects and welfare cultures. The Quarterly Journal of Economics, 115(3), 1019-1055.

Bloch, A., \& Schuster, L. (2005). At the extremes of exclusion: Deportation, detention and dispersal. Ethnic and Racial Studies, 28(3), 491-512.

Borjas, G. J. (1995). Ethnicity, neighborhoods, and human capital externalities. American Economic Review, 85(3), 365-390.

Borjas, G. J. (1998). To ghetto or not to ghetto: Ethnicity and residential segregation. Journal of Urban Economics, 44(2), 228-253.

Boswell, C. (2001). Spreading the Costs of Asylum Seekers: A Critical Assessment of Dispersal Policies in Germany and Britain. Anglo-German Foundation for the Study of Industrial Society.

Burnett, A., \& Peel, M. (2001). Asylum seekers and refugees in Britain: Health needs of asylum seekers and refugees. BMJ: British Medical Journal, 322(7285), 544.

Case, A. C., \& Katz, L. F. (1991). The company you keep: The effects of family and neighborhood on disadvantaged youths(No. w3705). National Bureau of Economic Research.

Chiswick, B. R., \& Miller, P. W. (1995). The endogeneity between language and earnings: International analyses. Journal of labor economics, 13(2), 246-288.

Chiswick, B. R., \& Miller, P. W. (1996). Ethnic networks and language proficiency among immigrants. Journal of Population Economics, 9(1), 19-35.

Chiswick, B. R., \& Miller, P. W. (2005). Do enclaves matter in immigrant adjustment?. City \& Community, 4(1), 5-35.

Coleman, J. S., Campbell, E. Q., Hobson, C. J., McPartland, J., Mood, A. M., Weinfeld, F. D., \& York R. L. (1966). Equality of educational opportunity. US Government Printing Office for Department of Health, Education and Welfare.

Cutler, D. M., \& Glaeser, E. L. (1997). Are ghettos good or bad?.The Quarterly Journal of Economics, 112(3), 827-872.

Damm, A. P. (2005). The Danish Dispersal Policy on Refugee Immigrants 1986-1998: A Natural Experiment? Århus: Aarhus School of Business, Department of Economics.

Damm, A. P. (2009a). Determinants of recent immigrants' location choices: quasi-experimental evidence. Journal of Population Economics, 22(1), 145-174.

Damm, A. P. (2009b). Ethnic enclaves and immigrant labor market outcomes: Quasi-experimental evidence. Journal of Labor Economics, 27(2), 281-314.

Damm, A. P., \& Rosholm, M. (2010). Employment effects of spatial dispersal of refugees. Review of Economics of the Household, 8(1), 105-146.

Damm, A. P., \& Dustmann, C. (2014). Does growing up in a high crime neighborhood affect youth criminal behavior?. American Economic Review, 104(6), 1806-32.

Edin, P. A., Fredriksson, P., \& Åslund, O. (2003). Ethnic enclaves and the economic success of immigrants-Evidence from a natural experiment. The quarterly journal of economics, 118(1), 329357. 
Edin, P. A., Fredriksson, P., \& Åslund, O. (2004). Settlement policies and the economic success of immigrants. Journal of Population Economics, 17(1), 133-155.

Ersbøll, Eva. 2015. Report on Citizenship Law: Denmark. European University Institute, Florence, Robert Schuman Centre for Advanced Studies, EUDO Citizenship Observatory.

Flygtningenævnet (1999). Flygtningencevnet - Formandskabet - 8. beretning 1999. http://www.fln.dk/ /media/FLN/Publikationer\%20og\%20notater/Publikationer/Beretninger/8 beretning 1999.ashx

Hahn, J., Todd, P., \& Van der Klaauw, W. (2001). Identification and estimation of treatment effects with a regression-discontinuity design. Econometrica, 69(1), 201-209.

Habyarimana, J., Humphreys, M., Posner, D. N., \& Weinstein, J. M. (2007). Why does ethnic diversity undermine public goods provision?. American Political Science Review, 101(4), 709-725.

Hainmueller, J., \& Hangartner, D. (2013). Who gets a Swiss passport? A natural experiment in immigrant discrimination. American Political Science Review, 107(1), 159-187.

Hainmueller, J., Hangartner, D., \& Pietrantuono, G. (2015). Naturalization fosters the long-term political integration of immigrants. Proceedings of the National Academy of Sciences, 112(41), 12651-12656.

Hainmueller, J., Hangartner, D., \& Pietrantuono, G. (2017). Catalyst or crown: does naturalization promote the long-term social integration of immigrants? American Political Science Review, 111(2), 256-276.

Hainmueller, J., Hangartner, D., \& Ward, G. (2019). Acquisition of Citizenship Increases the LongTerm Earnings of Marginalizaed Immigratns. https://osf.io/preprints/socarxiv/24qas/

Harder, N., Figueroa, L., Gillum, R. M., Hangartner, D., Laitin, D. D., \& Hainmueller, J. (2018). Multidimensional measure of immigrant integration. Proceedings of the National Academy of Sciences, 115(45), 11483-11488.

Lazear, E. P. (1999). Culture and language. Journal of political Economy, 107(S6), S95-S126.

Larsen, B. R. (2011). Becoming part of welfare Scandinavia: Integration through the spatial dispersal of newly arrived refugees in Denmark. Journal of Ethnic and Migration Studies, 37(2), 333-350.

Marbach, Moritz, Jens Hainmueller and Dominik Hangartner. (2018). The long-term impact of employment bans on the economic integration of refugees. Science advances, 4(9), eaap9519

Martén, L., Hainmueller, J., \& Hangartner, D. (2019). Ethnic networks can foster the economic integration of refugees. Proceedings of the National Academy of Sciences, 116(33), 1628016285.

McCrary, J. (2008). Manipulation of the running variable in the regression discontinuity design: A density test. Journal of econometrics, 142(2), 698-714.

Mossaad, N., Ferwerda, J., Lawrence, D., Weinstein, J. M., \& Hainmueller, J. (2018). Determinants of refugee naturalization in the United States. Proceedings of the National Academy of Sciences, 115(37), 9175-9180.

Nielsen, C. P., \& Jensen, K. B. (2006). Integrationslovens betydning for flygtninges boscetning. Köpenhamn: AKF-förlag.

Portes, A. (1987). The social origins of the Cuban enclave economy of Miami. Sociological perspectives, 30(4), 340-372.

Portes, A. (1998). Social capital: Its origins and applications in modern sociology. Annual review of sociology, 24(1), 1-24. Robinson, V. (1989). Up the creek without a paddle? Britain's boat people ten years on. Geography, 74(4), 332-338.

Robinson, V., \& Hale, S. (1989). The geography of Vietnamese secondary migration in the UK (No. 10). Warwick: Centre for Research in Ethnic Relations. 
Robinson, V., \& Coleman, C. (2000). Lessons learned? A critical review of the government program to resettle Bosnian quota refugees in the United Kingdom. International Migration Review, 34(4), $1217-1244$.

Sales, R. (2002). The deserving and the undeserving? Refugees, asylum seekers and welfare in Britain. Critical social policy, 22(3), 456-478.

Spicer, N. (2008). Places of exclusion and inclusion: Asylum-seeker and refugee experiences of neighbourhoods in the UK. Journal of ethnic and migration studies, 34(3), 491-510.

Zetter, R., \& Pearl, M. (2000). The minority within the minority: refugee community-based organisations in the UK and the impact of restrictionism on asylum-seekers. Journal of Ethnic and Migration Studies, 26(4), 675-697.

Åslund, O. (2005). Now and forever? Initial and subsequent location choices of immigrants. Regional Science and Urban Economics, 35(2), 141-165.

Åslund, O., \& Fredriksson, P. (2009). Peer effects in welfare dependence quasi-experimental evidence. Journal of human resources, 44(3), 798-825.

Åslund, O., Edin, P. A., Fredriksson, P., \& Grönqvist, H. (2011). Peers, neighborhoods, and immigrant student achievement: Evidence from a placement policy. American Economic Journal: Applied Economics, 3(2), 67-95. 


\section{Supplementary Information (not for publication)}

Supporting Identification Checks

Figure S.1. Sensitivity over Varying Bandwidths

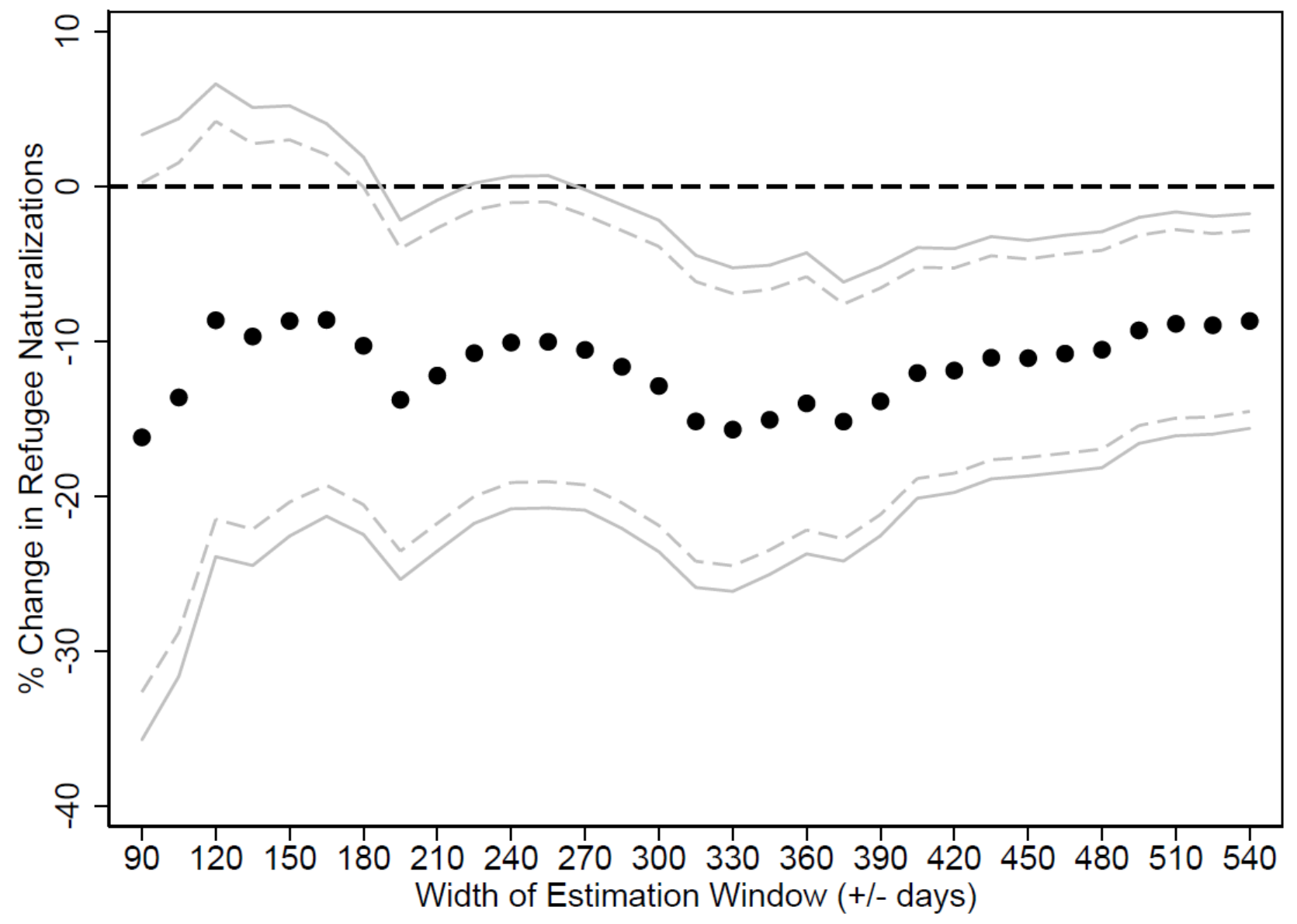

Note: The figure shows the estimated effect at the forced placement cutoff over varying bandwidths. The filled black circles represent point estimates as a function of the bandwidth. The grey solid and dashed lines show the $90 \%$ and $95 \%$ confidence intervals, respectively. The effect estimates are remarkably stable over varying bandwidths. 
Figure S.2. Test for Discontinuities at Placebo Cutoffs

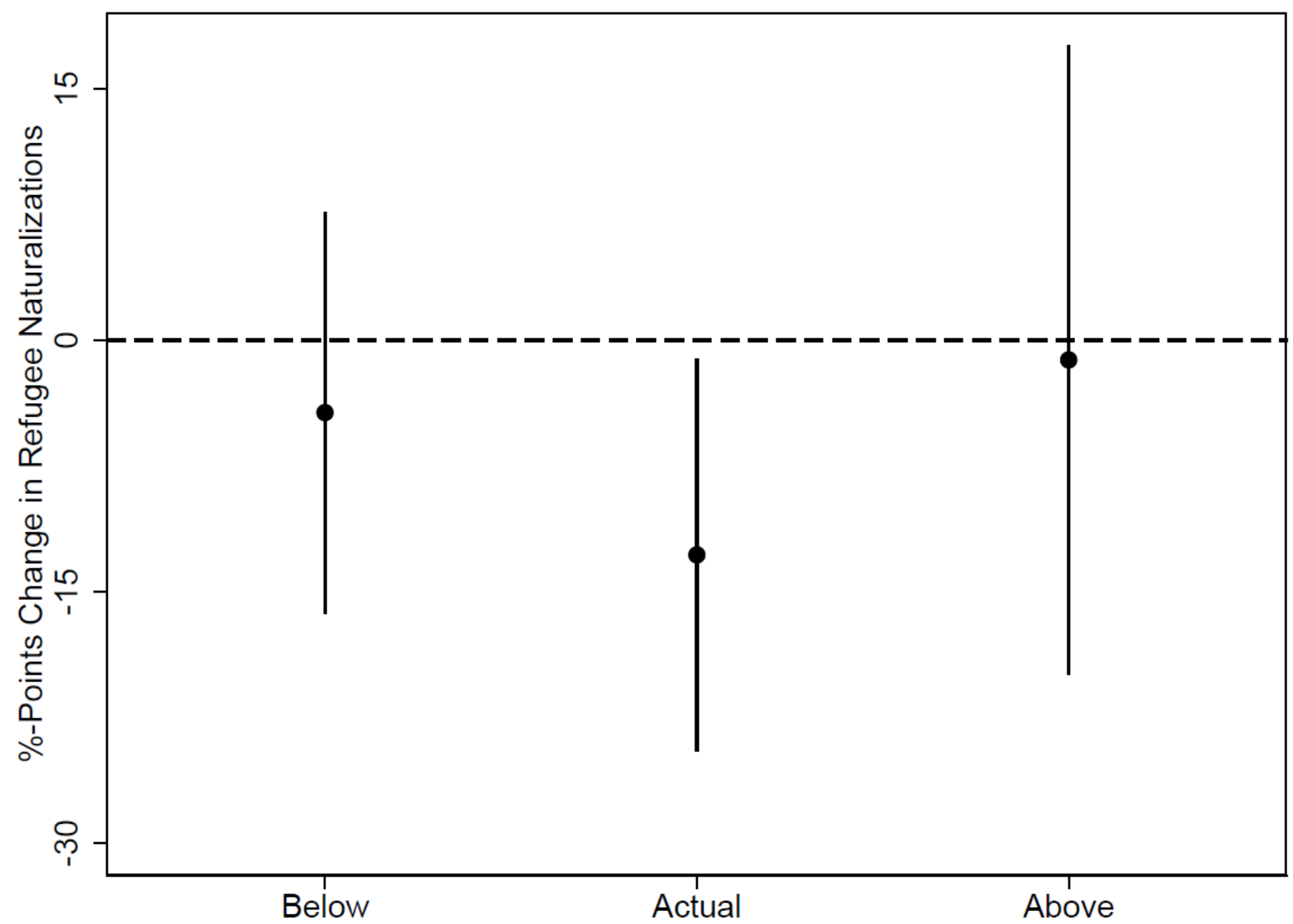

Note: Placebo effect estimates above and below the true cutoff (with $95 \%$ confidence interval). The placebo estimate below the true cutoff uses only observations under the true cutoff, and the placebo cutoff is set to the median. The placebo estimate above the true cutoff uses only observations over the true cutoff, and the placebo cutoff is set to the median. The figure demonstrates that there are no jumps at placebo cutoffs and indicates that the effect at the true cutoff is indeed a consequence of the policy change rather than an artefact of a jumpy relationship between the forcing variable and the naturalization outcome. 
Figure S.3. Test for Sorting Around the Forced Placement Cutoff
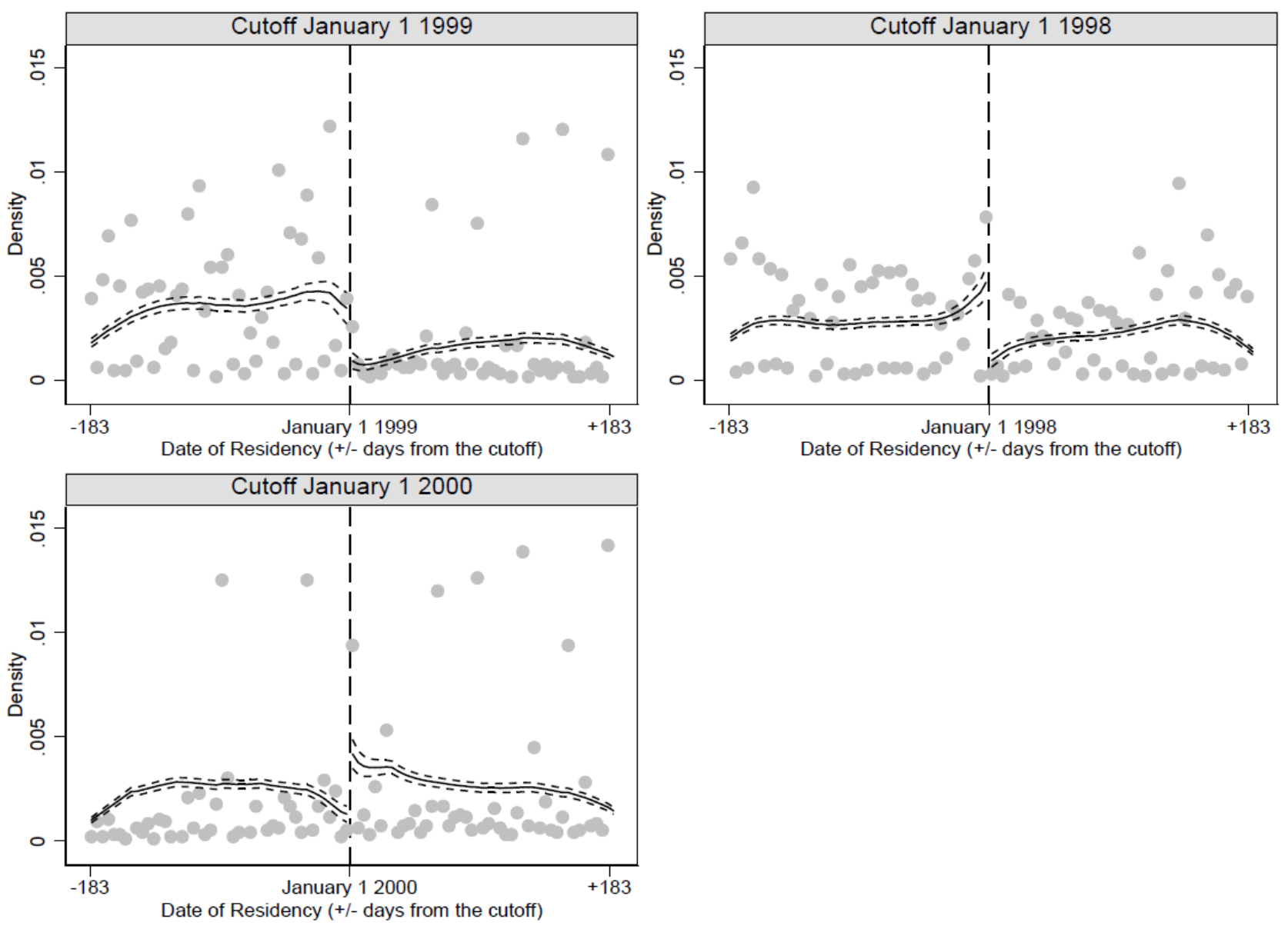

Note: The figure shows estimated densities of the distribution of refugee residencies on both sides of the cutoffs. There is a difference in densities at the cutoff of January 11999 (top left panel), which would suggest a violation of the no sorting assumption. However, the top right and bottom left panel shows similar differences in the densities at the cutoff of January 11998 and January 1 2000, respectively. Combined with the qualitative argument that refugees were not able to anticipate the cutoff and submit an asylum application in due time to get under the old placement rules and the empirical evidence from Figure 1, that showed no signs of discontinuities in any confounding characteristics of the refugees, this altogether suggests that the difference in densities does not reflect sorting, but rather is due to random factors. 
Table S.1. Overall Effect on Naturalization from Applying the RD Design

\begin{tabular}{lcc}
\hline \hline Model & $(1)$ & $(2)$ \\
\hline Treatment effect & $-12.79^{* *}$ & $-14.20^{* * *}$ \\
& $(5.93)$ & $(4.85)$ \\
\hline Residency & -0.02 & 0.03 \\
& $(0.03)$ & $(0.03)$ \\
Treatment $x$ Residency & 0.04 & 0.04 \\
& $(0.03)$ & $(0.04)$ \\
\hline Covariates & $X$ & $\checkmark$ \\
\hline Observations & 1,650 & 1,650 \\
\hline \hline
\end{tabular}

Note: Regression coefficients from local linear regression; standard errors clustered by first municipality in parentheses. ${ }^{*} P<0.10, * * P<0.05, * * * P<0.01$. The outcome is coded as 0 or 100 such that the effect estimates are measured in percentage points.

Table S.2. RD Effect on Secondary (Inter-Municipality) Migration

\begin{tabular}{lcccccccc}
\hline \hline Model & $(1)$ & $(2)$ & $(3)$ & $(4)$ & $(5)$ & $(6)$ & $(7)$ & $(8)$ \\
\hline Year & 2000 & 20001 & 2002 & 2003 & 2004 & 2005 & 2006 & 2007 \\
\hline Treatment effect & $22.89^{* * *}$ & $26.56^{* * *}$ & $26.70^{* * *}$ & $22.42^{* * *}$ & 22.88 & 20.39 & 11.96 & 10.75 \\
& $(6.41)$ & $(6.75)$ & $(6.74)$ & $(7.71)$ & $(7.19)$ & $(7.48)$ & $(7.71)$ & $(7.91)$ \\
\hline Residency & 0.03 & 0.02 & 0.03 & 0.04 & $0.06 *$ & 0.05 & 0.05 & $0.07 *$ \\
& $(0.04)$ & $(0.04)$ & $(0.04)$ & $(0.04)$ & $(0.04)$ & $(0.04)$ & $(0.04)$ & $(0.04)$ \\
Treatment x Residency & $-0.19 * * *$ & $-0.18^{* * *}$ & $-0.21^{* * *}$ & $-0.20^{* * *}$ & $-0.24 * * *$ & $-0.23 * * *$ & $-0.16^{* *}$ & $-0.22^{* * *}$ \\
& $(0.06)$ & $(0.06)$ & $(0.06)$ & $(0.06)$ & $(0.06)$ & $(0.06)$ & $(0.07)$ & $(0.06)$ \\
\hline Observations & 1,650 & 1,650 & 1,650 & 1,650 & 1,650 & 1,650 & 1,650 & 1,650 \\
\hline \hline
\end{tabular}

Note: Regression coefficients from local linear regression (w/o covariates); standard errors clustered by first municipality in parentheses. ${ }^{*} P<0.10,{ }^{* *} P<0.05$, ${ }^{* * *} P<0.01$. The outcome is coded as 0 or 100 such that the effect estimates are measured in percentage points. 
Table S.3. Matched Sample RD Effect Estimates

\begin{tabular}{lcc}
\hline \hline Model & $(1)$ & $(2)$ \\
\hline Outcome & Naturalization & Naturalization \\
& (matched sample) & (matched sample) \\
\hline Treatment effect & $-16.61^{* *}$ & $-17.88^{* *}$ \\
& $(7.80)$ & $(8.21)$ \\
\hline Residency & -0.00 & 0.04 \\
& $(0.03)$ & $(0.04)$ \\
Treatment $x$ Residency & 0.00 & 0.01 \\
& $(0.06)$ & $(0.06)$ \\
\hline Covariates & $\mathrm{X}$ & $\checkmark$ \\
\hline Observations & 1,055 & 1,055 \\
\hline \hline
\end{tabular}

Note: Matched sample regression coefficients from local linear regression; standard errors clustered by municipality in parentheses. $* \mathrm{P}<0.10$, ** $\mathrm{P}<0.05$, *** $\mathrm{P}<0.01$. The outcome is coded as 0 or 100 such that the effect estimates are measured in percentage points. 
Table S.4. Matched Sample RD Effect Estimates, by Municipality Subsamples

\begin{tabular}{|c|c|c|c|c|c|c|}
\hline Model & $(1)$ & $(2)$ & $(3)$ & $(4)$ & $(5)$ & $(6)$ \\
\hline Sample & $\begin{array}{c}\text { Greater are of Co- } \\
\text { penhagen }=\text { yes }\end{array}$ & $\begin{array}{c}\text { Greater are of } \\
\text { Copenhagen }= \\
\text { no }\end{array}$ & $\begin{array}{l}\text { Copenhagen, } \\
\text { Aarhus, Odense, } \\
\text { or Aalborg = yes }\end{array}$ & $\begin{array}{c}\text { Copenhagen, } \\
\text { Aarhus, Odense, } \\
\text { or Aalborg = no }\end{array}$ & $\begin{array}{c}\text { Copenhagen }= \\
\text { yes }\end{array}$ & $\begin{array}{c}\text { Copenhagen }= \\
\text { no }\end{array}$ \\
\hline Treatment effect & $\begin{array}{c}-24.82 * * * \\
(7.97)\end{array}$ & $\begin{array}{l}-10.07 \\
(11.66)\end{array}$ & $\begin{array}{l}-18.44 \\
(15.35)\end{array}$ & $\begin{array}{r}-13.66 \\
(8.36)\end{array}$ & $\begin{array}{l}-34.75 \\
(26.95)\end{array}$ & $\begin{array}{c}-14.78 * \\
(8.36)\end{array}$ \\
\hline Residency & $\begin{array}{c}0.02 \\
(0.05)\end{array}$ & $\begin{array}{l}-0.01 \\
(0.03)\end{array}$ & $\begin{array}{c}0.01 \\
(0.05)\end{array}$ & $\begin{array}{c}0.01 \\
(0.04)\end{array}$ & $\begin{array}{c}0.08 \\
(0.08)\end{array}$ & $\begin{array}{l}-0.03 \\
(0.03)\end{array}$ \\
\hline $\begin{array}{l}\text { Treatment } \times \text { Resi- } \\
\text { dency }\end{array}$ & $\begin{array}{r}0.05 \\
(0.09) \\
\end{array}$ & $\begin{array}{l}-0.03 \\
(0.09) \\
\end{array}$ & $\begin{array}{c}0.04 \\
(0.14) \\
\end{array}$ & $\begin{array}{l}-0.01 \\
(0.08) \\
\end{array}$ & $\begin{array}{c}0.10 \\
(0.24) \\
\end{array}$ & $\begin{array}{c}0.01 \\
(0.07) \\
\end{array}$ \\
\hline Covariates & $x$ & $\mathrm{x}$ & $\mathrm{x}$ & $\mathrm{x}$ & $x$ & $x$ \\
\hline Observations & 351 & 704 & 478 & 577 & 196 & 859 \\
\hline
\end{tabular}

Note: Matched sample regression coefficients from local linear regression; standard errors clustered by municipality in parentheses. * $\mathrm{P}<$ $0.10, * * \mathrm{P}<0.05, * * * \mathrm{P}<0.01$. The outcome is coded as 0 or 100 such that the effect estimates are measured in percentage points. 
Table S.5. RD Effect on Location Conduciveness (\% Co-ethnics and \% Immigrants)

\begin{tabular}{lcccc}
\hline \hline Model & $(1)$ & $(2)$ & $(3)$ & $(4)$ \\
\hline Outcome & \% Co-ethnics & \% Co-ethnics & \% Immigrants & \% Immigrants \\
\hline Treatment effect & $-2.10^{* *}$ & $-2.28^{* * *}$ & $-4.05^{* * *}$ & $-4.45^{* * *}$ \\
& $(0.95)$ & $(0.82)$ & $(1.29)$ & $(1.16)$ \\
\hline Residency & -0.00 & 0.00 & 0.00 & 0.00 \\
& $(0.01)$ & $(0.01)$ & $(0.01)$ & $(0.01)$ \\
Treatment $x$ Resi- & -0.01 & -0.01 & -0.01 & $-0.02^{*}$ \\
dency & $(0.01)$ & $(0.01)$ & $(0.01)$ & $(0.01)$ \\
\hline Covariates & $\mathrm{X}$ & $\checkmark$ & $\mathrm{x}$ & $\checkmark$ \\
\hline Observations & 1,650 & 1,650 & 1,650 & 1,650 \\
\hline Percent change & 33 & 36 & 33 & 36.0 \\
\hline \hline
\end{tabular}

Note: Regression coefficients from local linear regression; standard errors clustered by first municipality in parentheses. ${ }^{*} P<0.10, * * P<0.05, * * * P<0.01$. The outcome is coded as 0 or 100 such that the effect estimates are measured in percentage points. I observe the local concentrations January 1 2001. The concentrations are computed at the parish level, which is the smallest pre-defined administrative and geographically delimited unit in Denmark. In total, there were 2123 Danish parishes in 2015. In comparison, there were 98 municipalities, 600 zip codes, 1290 school districts, and 1390 voting stations. 
Table S.6. RD Effect on Naturalization, by Education

\begin{tabular}{|c|c|c|c|c|c|c|}
\hline Model & (1) & (2) & (3) & (4) & (5) & (6) \\
\hline Education & Low & Low & Medium & Medium & High & High \\
\hline Treatment effect & $\begin{array}{c}-21.04 * * * \\
(6.93)\end{array}$ & $\begin{array}{c}-22.69 * * * \\
(6.57)\end{array}$ & $\begin{array}{c}-6.59 \\
(12.06)\end{array}$ & $\begin{array}{c}-14.78 \\
(11.05)\end{array}$ & $\begin{array}{c}10.08 \\
(16.99)\end{array}$ & $\begin{array}{c}12.46 \\
(14.89)\end{array}$ \\
\hline Residency & $\begin{array}{c}0.04 \\
(0.04)\end{array}$ & $\begin{array}{c}0.05 \\
(0.04)\end{array}$ & $\begin{array}{l}-0.06 \\
(0.04)\end{array}$ & $\begin{array}{c}0.04 \\
(0.05)\end{array}$ & $\begin{array}{l}-0.06 \\
(0.07)\end{array}$ & $\begin{array}{l}-0.00 \\
(0.06)\end{array}$ \\
\hline Treatment $x$ Residency & $\begin{array}{l}-0.01 \\
(0.07)\end{array}$ & $\begin{array}{c}0.04 \\
(0.07)\end{array}$ & $\begin{array}{c}0.10 \\
(0.09)\end{array}$ & $\begin{array}{c}0.08 \\
(0.09)\end{array}$ & $\begin{array}{l}-0.10 \\
(0.16)\end{array}$ & $\begin{array}{l}-0.17 \\
(0.15)\end{array}$ \\
\hline Covariates & $x$ & $\checkmark$ & $x$ & $\checkmark$ & $x$ & $\checkmark$ \\
\hline Observations & 725 & 725 & 666 & 666 & 259 & 259 \\
\hline
\end{tabular}

Note: Regression coefficients from local linear regression; standard errors clustered by first municipality in parentheses. $* P<0.10, * * P<$ $0.05, * * * P<0.01$. The outcome is coded as 0 or 100 such that the effect estimates are measured in percentage points. 
Table S.7. Overall RD Effect on Naturalization. Excluding de facto Untreated

\begin{tabular}{lcc}
\hline \hline Model & $(1)$ & $(2)$ \\
\hline Treatment effect & $-12.79^{* *}$ & $-10.60^{*}$ \\
& $(5.93)$ & $(5.93)$ \\
\hline Residency & -0.02 & -0.03 \\
& $(0.03)$ & $(0.03)$ \\
Treatment x Residency & 0.04 & 0.05 \\
& $(0.05)$ & $(0.05)$ \\
\hline Including de facto untreated & $\checkmark$ & $x$ \\
\hline Observations & 1,650 & 1,580 \\
\hline \hline
\end{tabular}

Note: Regression coefficients from local linear regression; standard errors clustered by first municipality in parentheses. ${ }^{*} P<0.10, * * P<0.05, * * * P<0.01$. The outcome is coded as 0 or 100 such that the effect estimates are measured in percentage points.

Table S.8. Overall RD Effect on Naturalization. Country of Origin

\begin{tabular}{lccc}
\hline \hline Model & $(1)$ & $(2)$ & $(3)$ \\
\hline Treatment effect & $-12.79^{* *}$ & $-14.20^{* * *}$ & $-12.52^{* *}$ \\
& $(5.93)$ & $(4.85)$ & $(5.76)$ \\
\hline Residency & -0.02 & 0.03 & 0.03 \\
& $(0.03)$ & $(0.03)$ & $(0.03)$ \\
Treatment x Residency & 0.04 & 0.04 & 0.04 \\
& $(0.05)$ & $(0.04)$ & $(0.05)$ \\
\hline Individual characteristics & $\mathrm{x}$ & $\checkmark$ & $\checkmark$ \\
Grouped origin & $\mathrm{x}$ & $\checkmark$ & $\checkmark$ \\
Country of origin dummies & $\mathrm{x}$ & $\mathrm{x}$ & 1,650 \\
\hline Observations & 1,650 & 1,650 & $\checkmark$ \\
\hline \hline
\end{tabular}

Note: Regression coefficients from local linear regression; standard errors clustered by first municipality in parentheses. ${ }^{*} P<0.10, * * P<0.05, * * * P<0.01$. The outcome is coded as 0 or 100 such that the effect estimates are measured in percentage points. 
Table S.9. Overall RD Effect on Naturalization. Alternative Specifications

\begin{tabular}{lcc}
\hline \hline Model & $(1)$ & $(2)$ \\
\hline Specification & Local linear (parametric) & Local quadratic (parametric) \\
\hline Treatment effect & $-12.79^{* *}$ & -15.73 \\
& $(5.93)$ & $(10.38)$ \\
\hline BW $( \pm$ days $)$ & \pm 183 & \pm 183 \\
\hline Observations & 1,650 & 1,650 \\
\hline \hline
\end{tabular}

Note: RD effect estimates; standard errors clustered by first municipality in parentheses. ${ }^{*} P<0.10$, ** $P<0.05$, *** $P<0.01$. The outcome is coded as 0 or 100 such that the effect estimates are measured in percentage points. 